\title{
CONSTRUCTIVE ALIGNMENT OF A FLIPPED DESIGN AUTOMATION LECTURE
}

\author{
Paul Christoph GEMBARSKI \\ Leibniz University Hannover, Germany
}

\begin{abstract}
Design automation in mechanical engineering requires students not only to obtain competences in the application of computer aided design software and the creation of knowledge-based product models. Future knowledge engineers need e.g., communicational skills in order to acquire the relevant knowledge for later implementation in design automation systems, or skills for planning, modelling, and exploring a design solution space. In a flipped classroom setup, where the responsibility for the learning process and thus several degrees of freedom regarding topics and their weighting are transferred to the students, a later summative assessment needs to fulfil two basic requirements: First to reflect the individual learning progress of a student, second to discover if the higher learning goals of the course are met. Constructive alignment is a technique to relate teaching activities, learning outcomes and assessment to each other and to the competences that a learner should acquire. The present paper reports about the assessment for a flipped classroom design automation lecture. Starting from the educational objectives and the learning activities, two different assessment mechanisms are characterized: A semester project where two or three students works as a team of knowledge engineers to create a knowledge-based engineering system, e.g., a product configurator, and an oral exam where each student has the opportunity to report about his or her individual learning process and dispute this with the teaching staff.
\end{abstract}

Keywords: Knowledge-based engineering, flipped classroom, constructive alignment

\section{INTRODUCTION}

Computer-aided design (CAD) systems are among the fundamental software applications with which mechanical engineering students come into contact. The definition of shape and product properties in these systems is fundamental to virtual prototyping and knowledge-based design [1,2]. A capstone course for design automation in this field requires students not only to obtain competences in the application of CAD software and knowledge-based product modelling but also methodological and selfcompetences. Future knowledge engineers need e.g., communicational skills in order to acquire the relevant knowledge for later implementation in design automation systems, or skills for planning, modelling, and exploring a design solution space $[3,4]$.

Teaching design automation in a flipped classroom transfers the responsibility for the learning process and thus several degrees of freedom regarding topics and their weighting to the students. Additionally, working on self-chosen semester projects in a team opens up the opportunity for the students to carry own knowledge, experiences, and challenges from past design projects into the course, making the range of possible projects and the corresponding knowledge enhancement broad [5]. Considering this, a later summative assessment needs to fulfil two basic requirements: First to reflect the individual learning progress of a student, second to discover if the higher learning goals of the course are met.

Constructive alignment is a technique to relate teaching activities, learning outcomes and assessment to each other and to the competences that a learner should acquire $[6,7]$. Two fundamental conceptions therefore are that first learning is the result of students gaining meaning from activities and second teaching needs operationalization according to learning outcomes and supporting students in achieving them [8].

The present paper discusses constructive alignment of a design automation lecture and focusses then on its assessment mechanisms. It is structured as follows: The following section 2 presents a brief theoretical background focusing on the flipped / inverted classroom concept, constructive alignment, and the context of knowledge-based engineering. Afterwards, section 3 deduces constructive alignment 
for the design automation lecture using a methodology for creating knowledge-based systems. Section 4 then focusses on the assessment methods, before sections 5 and 6 present discussion and conclusion.

\section{THEORETICAL BACKGROUND}

\subsection{Flipped classroom}

Although the shift of lecture time and out-of-class passive learning activities is widely known from distance education, flipping, or inverting the classroom is a different pedagogical approach [9]. The idea is to intentionally push passive learning activities like listening to lectures outside of class while active learning, like laboratories, discussions and more complex problem solving is experienced in-class [10]. The consequence is that the consumption of learning material is independent from place and time and contact time between teacher and students is efficiently used [11]. Additionally, in combination with problem-based learning, group collaboration and a high responsibility for their own learning process the concept is able to encourage students to better explore the course content compared to a traditional lecture. The flipped classroom concept dates back to the late 1990s but is becoming increasingly popular with the intensive use of the Internet, as asynchronous teaching materials can be easily delivered online and through learning management systems. Nevertheless, the use of flipped classroom is not widespread in engineering disciplines and there is comparatively little research regarding its impact on engineering education in general $[12,13]$.

\subsection{Constructive Alignment}

Teaching means to transmit knowledge to students. Here, constructive alignment sets the focus on operationalizing quality of teaching and learning with three key questions [6]:

1. What is the intended learning outcome that a student should have obtained after passing the course?

2. What are the teaching and learning activities that are necessary to carry out in order to get to the learning outcome? Is it e.g., application of a theory, generating new ideas on basis of requirements, solving problems, or diagnosing?

3. What are authentic assessment methods in order to reflect the learning activities and check if the learning outcome is really met? Especially in design engineering a method shift from classical exams towards project assessments, customer journeys or communicating with clients is emphasized.

The benefits of constructive alignment for the teacher are a higher likelihood that students will learn in the wanted way, the development of trust and shared goals between teacher and student, and growing student confidence in their own learning [14]. A prerequisite is total transparency: Before the learning begins, teachers clearly express what students should learn and how to express their learning by themselves. Another side effect is greater standardization and fairness of grading [15].

\subsection{Knowledge-based Engineering}

Knowledge-based engineering (KBE) aims at creating product models that can be easily adapted to new requirements and used to automate design tasks $[16,17]$. KBE thus is useful for design tasks with a high number of routine tasks like configuration design activities but also for decision support for human designers and co-creation between e.g., human designers and computer-based agents [18, 19]. Today's CAD systems offer different possibilities to establish knowledge-based models, like the use of parametric constraints and equations, design rules or the integration of external knowledge sources and reasoning [20]. Knowledge engineering, i.e., acquiring relevant knowledge from human and non-human resources and formalizing it according to the later purpose, and building knowledge-based product models require theoretical knowledge, but rather experience and skills in working in teams, project management and communication as well [21, 22]. In order to be relevant, a corresponding teaching setup must consider such educational objectives and give the students the opportunity to gather routine by doing and experiencing projects [23].

\section{CONSTRUCTIVE ALLIGNMENT OF A DESIGN AUTOMATION LECTURE}

The application of constructive alignment raises the question: Align to what? As described earlier, a design automation lecture should enable students to work as knowledge engineers and let them create knowledge-based product models. In order to get to learning objectives, a look into methodologies for 
creating such models is a first hint. As an example, MOKA, the Methodology and tools oriented to knowledge-based engineering application [21] can serve.

Here, Stokes presents a process model, which is applicable independently from domains. The phases are:

1. Identify: Investigate business needs, determine type of the KBE system, and examine knowledge resources.

2. Justify: Derive acceptance criteria from requirements, generate project and business plan.

3. Capture: Collect knowledge from non-human and human resources, structure, check for purpose and file.

4. Formalize: Develop product and process model, certify formal knowledge model, store repository, and prepare for implementation.

5. Package: Translate formal knowledge model into working KBE system.

6. Activate: Involve stakeholders, implement software, and train users.

This enumeration allows formulating learning objectives for future knowledge engineers. To those belong:

1. Knowledge engineers need to investigate requirements for KBE systems and estimate implementation efforts.

2. They have to orient at methods for creation of KBE systems in order to derive project plans.

3. A knowledge engineer needs profession in acquiring knowledge from different information sources, including human experts.

4. Knowledge engineers need profound routine in formalizing knowledge into KBE system features and reasoning.

5. They also have to argue which way of implementation is superior and in which way it fits to the requirements.

6. A knowledge engineer needs good skills in communication and visualization in order to involve customers and later users of the KBE system.

At Leibniz University of Hannover, the lecture Knowledge-Based CAD 1 - Configuration and Design Automation addresses five major topics to operationalize the learning objectives, which is parametric CAD models and part families, advanced assembly control via skeleton techniques, spreadsheet-driven design, knowledge engineering and methodologies as well as product configurators and expert systems. For each of them, learning material according to the flipped classroom was created like commented lecture slides, screen casts or video tutorials. Attendance time is 10 sessions of 150 minutes each. Usually, the instructor engages the students at the beginning with a small warm-up task targeting the prepared course material. Then, groups of three to five students complete modelling tasks related to the topic at hand as learning activities. Meanwhile, the teacher moderates and guides the learning process of the groups. Each session is concluded with a wrap-up and participants then upload their results to a learning management system for all participants to access. An exception to this template is the Knowledge Engineering and Methods topic, which requires students to work in groups to prepare a poster session on a specific method to be presented and discussed in a Gallery Walk. After this session, the students form to learning tandems or triplets and negotiate an accompanying semester project with the teachers. Therefore, the students need to formulate a synopsis of max. two thousand symbols and a preliminary project plan as Gantt chart. This already contributes to the first learning objective of investigating the task and planning implementation. The teachers then approve this, and the students can start execution. Here, the task is to implement e.g., a product configurator but for later grading, the documentation of the project is decisive.

\section{ASSESSMENT MECHANISMS}

The project documentation is one of two pillars of the assessment in the lecture Knowledge-Based CAD 1 -Configuration and Design Automation. The documentation has to answer the following questions:

- Relevance of the project: Did the team generally find a solution for the targeted problem?

- Validity of project results: Are the models generated based on comprehensible facts, calculation bases, etc.? Were useful methods and tools used for the models generated? 
- Reliability and robustness of project results: Have alternative solutions been discussed? Would the use of other methods lead to the same goal? Have the limitations of the model been tested and named?

- Traceability of the documentation: Does the documentation describe not only the results but also the way to get there? Has the choice of methods and tools been adequately derived and justified? Can models be replicated by others with the help of the documentation?

- Form of documentation: Is the documentation structured in a meaningful way, do directories and appendices exist? Are spelling and punctuation, correct? Are the graphics appropriate to their information content?

Before starting project work, the students get to know about the above questions in order to meet the requirement of transparency about assessment criteria and their weighting. Additionally, the teachers offer to scan through a preliminary version of the documentation. This creates a typical situation from the sixth phase of the MOKA cycle: Customers and users test the implemented system as well as its documentation, ask questions and give remarks for improvement. This pillar mainly targets on the first five learning objectives stated above.

As the documentation is the result of group work, a second pillar was necessary to reflect the individual learning process of each student. The teachers chose an oral examination for this. It follows the principle that the student first has the opportunity to reflect his or her learning on one of the major lecture topics by him/herself. After preparation, the student gets seven minutes of time, two meters of whiteboard and four pens as resources for the presentation. Afterwards, the teaching staff asks questions on this and interviews the student about different fields of knowledge. For grading, both width and depth of the knowledge fields are relevant but also the form of presentation (e.g., capability of visualization) in the first part of the examination. Consequently, this assessment aims more on the last learning objective.

\section{EXPERIENCES}

Within the last four semesters, nearly 70 bachelor and master students in mechanical engineering passed the course, which resulted in 28 semester projects. An average documentation consists of 40 pages and 30 pages of appendix where the students paste code form their KBE system, additional diagrams e.g., for the configuration process or the formal knowledge model known from the MOKA cycle. Until now, all tandems or triplets took the opportunity to let the teachers review a preliminary version of the documentation. The teachers made the following observations, which did not significantly differ between the student groups over time:

- Argumentation skills: The majority of documentations has initially quite a superficial argumentation of the chosen way of implementation. An example: If students chose VBA to create a product configurator this is usually due to the lack of a context sensitive user interface in other implementations. After mentioning, this point is usually addressed with an additional section and three to four statements why this way is superior to others.

- Project management skills: What was astonishing is the fact that nearly a third of the documentations showed that the students take not sufficient time for planning. Requirements that are fuzzy and not clearly examined at the beginning of the project often lead to the necessity to rebuild parts of the knowledge model, e.g., when design rules cannot be translated into a formal model. Nonetheless, a complete redesign of a KBE system did not occur until now.

- Documentation of the knowledge model: Here, the students are commonly safe in handling. The knowledge model is usually documented as parameter plan, configuration process flow chart, spreadsheet implementation and design rules.

- Visualization skills: The use of diagrams and figures is in average good. Comparing the preliminary version to the final version, the record of the solution space is initially not supported by pictures that show different configurations that the KBE system is able to generate. Here after mentioning, some students still dread to show this.

Regarding the oral examination, the students chose commonly either spreadsheet driven design or expert systems as starting points for their presentation. However, these presentations differ from each other and comply with our requirement of individuality. Visualization has a quite broad spectrum in the examination: Most students use prepared index card as templates for e.g., diagrams that are put on the white board. Some students use sticky notes instead and try to involve the teachers in the presentation. 
Regarding student feedback, the uncommon assessment formats at our university challenge the students. Nonetheless, due to the transparency in grading and in the learning objectives, our students do not feel this as threat. Especially for the bachelor students the project documentation is felt as a good practice since in their studies written reports are a shortcoming. Some of our students thus feel better prepared for their thesis after completing the course.

\section{CONCLUSIONS}

The orientation along the specified learning objectives, which is forced by constructive alignment, was a good foundation for the creation of the lecture Knowledge-Based CAD 1-Configuration and Design Automation. For the teachers, the focus on the objectives led to a good choice of learning activities for both preparation and presence time of the flipped classroom lecture. For the students, especially the assessment in form of natural mechanics in the later profession as knowledge engineer are a clear benefit. Meanwhile, the teachers offer outstanding students tandems and triplets to derive scientific papers from the documentation and the data of the semester project.

Constructive alignment is comfortable as it enables a top-down planning of a lecture. The definition of learning and teaching activities leads automatically to a process view and thus to the identification of inputs, outputs, and resources. As it is shown in conjunction with a flipped classroom, this also works with certain degrees of freedom. However, the consideration of all possible prerequisites of our students and the reflection of different learner types is exhausting and not always possible beforehand. Consequently, continuous feedback between students and teachers about learning obstacles, curricular constraints or working in the presence is still a value. And this cannot be planned, letting this happen certainly can.

\section{REFERENCES}

[1] Dankwort C. W., Weidlich R., Guenther B., and Blaurock J. E. Engineers' CAx education - it is not only CAD. Computer-Aided Design, 2004, 36(14), pp. 1439-1450.

[2] Stroud I. and Nagy H. Solid modelling, and CAD systems: how to survive a CAD system. 2011 (Springer, Berlin Heidelberg).

[3] Milton N. R. Knowledge technologies. 2008 (Polimetrica sas, Monza).

[4] Schreiber G., Wielinga B., de Hoog R., Akkermans H., and Van de Velde W. CommonKADS: A comprehensive methodology for KBS development. IEEE expert, 1994, 9(6), pp. 28-37.

[5] Gembarski P. C. Good Idea or Bad Idea? - Teaching Knowledge-Based Engineering in a Flipped Classroom. In Proceedings of the 22nd International Conference on Engineering and Product Design Education (E\&PDE2020). Herning, September 2020.

[6] Biggs J. Enhancing teaching through constructive alignment. Higher education, 1996, 32(3), pp. 347-364.

[7] Brabrand C. Constructive alignment for teaching model-based design for concurrency. In Transactions on petri nets and other models of concurrency I, 2008, pp. 1-18 (Springer, Berlin, Heidelberg).

[8] Borrego M. and Cutler S. Constructive alignment of interdisciplinary graduate curriculum in engineering and science: An analysis of successful IGERT proposals. Journal of Engineering Education, 2010, 99(4), pp. 355-369.

[9] Enfield J. Looking at the impact of the flipped classroom model of instruction on undergraduate multimedia students at CSUN. TechTrends. 2013, 57(6), pp. 14-27.

[10] Akçayır G. and Akçayır M. The flipped classroom: A review of its advantages and challenges. Computers \& Education, 2018, 126, pp. 334-345.

[11] Gannod G., Burge J., and Helmick M. Using the inverted classroom to teach software engineering. In 2008 ACM/IEEE 30th International Conference on Software Engineering. 2008, pp. 777-786.

[12] Kerr B. The flipped classroom in engineering education: A survey of the research. In 2015 International Conference on Interactive Collaborative Learning (ICL). 2015, pp. 815-818.

[13] Chao C. Y., Chen Y. T. and Chuang K. Y. Exploring students' learning attitude and achievement in flipped learning supported computer aided design curriculum: A study in high school engineering education. Computer Applications in Engineering Education, 2015, 23(4), pp. 514526.

[14] Nightingale S., Carew A. L., and Fung J. Application of constructive alignment principles to 
engineering education: have we really changed? In Proceedings of the 2007 AaeE Conference. Melbourne, 2007.

[15] McMahon T. and Thakore H. Achieving Constructive Alignment: Putting Outcomes First. Quality of Higher Education, 2006, 3, pp. 10-19.

[16] Verhagen W. J. C., Bermell-Garcia P., van Dijk R. E. C., and Curran R. A critical review of Knowledge-Based Engineering: An identification of research challenges. Advanced Engineering Informatics, 2012, 26(1), pp. 5-15.

[17] Hopgood A. A. Intelligent systems for engineers and scientists. 2012 (CRC press, Boca Raton).

[18] Gembarski P. C. On the Conception of a Multi-agent Analysis and Optimization Tool for Mechanical Engineering Parts. In Agents and Multi-Agent Systems: Technologies and Applications 2020, 2020, pp. 93-102 (Springer, Singapore).

[19] Li H., Gembarski P. C., and Lachmayer R. Template-based design for design co-creation. In Proceedings of the Fifth International Conference on Design Creativity (ICDC 2018). 2018, pp. 387-394.

[20] Gembarski P. C. Three Ways of Integrating Computer-Aided Design and Knowledge-Based Engineering. In Proceedings of the Design Society: DESIGN Conference, Vol. 1, pp. 1255-1264 (Cambridge University Press, Cambridge).

[21] Stokes M. Managing engineering knowledge: MOKA: methodology for knowledge based engineering applications. 2001 (Professional Engineering Publishing, London).

[22] Chandrasegaran S. K., Ramani K., Sriram R. D., Horváth I., Bernard A., Harik R. F., and Gao W. The evolution, challenges, and future of knowledge representation in product design systems. Computer-aided design, 45(2), 2013, pp. 204-228.

[23] Gembarski P. C. and Lachmayer R. The Hanover Knowledge-Based-Design-Lab: A ProjectOriented Capstone Course in Engineering Design. In Proceedings of the 20th International Conference on Engineering and Product Design Education (E\&PDE2018). 2018, pp. 662-667. 